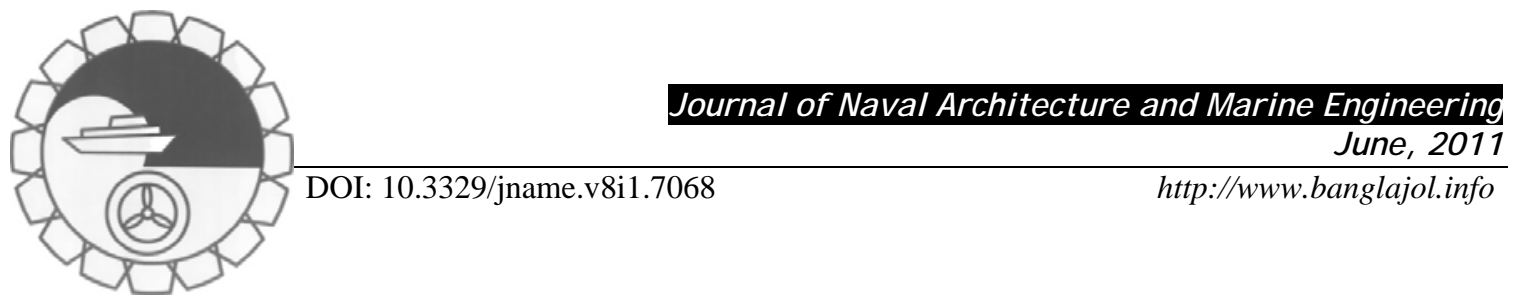

\title{
Book Review: Cost Management in Shipbuilding
} by Jan O. Fischer, Gerd Holbach

Shipbuilding is characterized by the specific features of the unit production, high complexity and long project duration as well as global competition. Therefore, the shipbuilding process requires special cost management procedures. Against this background the authors demonstrate how effective cost management methods and processes strengthen and ensure a manufacturer's competitiveness in the maritime industry. A main focus of the book is on the available system support for efficiently planning, analysing and controlling a ship's costs in all building phases. In addition to design and manufacturing, also the in-service phase of the ship is included in order to optimise the whole life cycle cost.

The book is based on knowledge, which the authors gained by more than 10 years experience in industrial cost management and shipbuilding and addresses specialists confronted with the practical challenges of cost management in everyday business. 